\title{
Cultivating a Self-Centered Sociality?
}

\section{A Reconstruction of the Structural Features of Everyday Digital Interaction between Young People}

\author{
Boris ZIZEK \\ Institute for Educational Sciences, Leibniz University Hannover, Germany \\ boris.zizek@iew.uni-hannover.de
}

\begin{abstract}
The present study uses texting interactions from different digital contexts to reconstruct the structural features of everyday digital interaction between young people in order to examine the socializing tendencies of growing up in the digital age. Secondly, it will be reflected which of these characteristics is cultivated by the structure of the digital communication platforms, that is, stimulated and encouraged by the architecture of the platforms. Third, in order to further differentiate this question, it is considered in a cultural-historical perspective which technically cultured structures of interaction build on and promote long-lasting cultural tendencies. Finally, all three focuses on the impact of these interaction structures and tendencies on the experience, attitude and development of adolescents.
\end{abstract}

\section{Keywords}

adolescence - structural characteristics of everyday digital interaction - objective hermeneutics - digital socialization

\section{Introduction}

Back in 2010, the New York Times headlined 'If your kids are awake, they're probably online.' Although this is, of course, a journalistic over-accentuation, the figures for duration of use and accessibility have been showing a clear and impressive trend in this direction worldwide for years. 
The Internet and social media have developed in a relatively short time into an everyday space of experience with novel interaction possibilities, which, in particular through the possibilities of the smartphone, permeates the everyday life of the adolescents potentially temporally and locally (Common Sense Media 2015; Shell Study 2015; Turkle 2015). Some even explain it as a normal case, for example, a seventeen-year-old boy from Hanover in his WhatsApp Moto 'You only go offline if you have failed online'.

So far, particularly more eye-catching phenomena such as cyberbullying, the duration of use or the contents of video games have been thoroughly investigated (JIM 2018, Shell 2019). On the other hand, the change in the everyday social interaction in the technically mediated and structured communication spaces is under-researched. This is remarkable, especially since here the deep and long-term effect on the coexistence and autonomy development of adolescents is to be assumed.

The present study uses texting interactions from different digital contexts to reconstruct the structural features of everyday digital interaction between young people in order to examine the socializing tendencies of growing up in the digital age. In the sense of a reconstructive socialization theory (Zizek, 2018), it assumes that these interaction structures deeply shape the adolescents in their experiences. Secondly, it will be reflected which of these characteristics is cultivated by the structure of the digital communication platforms, that is, stimulated and encouraged by the architecture of the platforms (Zizek \& Andermann, 2020). Third, in order to further differentiate this question, it is considered in a cultural-historical perspective which technically cultured structures of interaction build on and promote long-lasting cultural tendencies. Finally, all three focuses on the impact of these interaction structures and tendencies on the experience, attitude and development of adolescents.

\section{Structures of Everyday Digital Interactions and Communication Platforms and Their Impact on Adolescent Experience, Attitudes and Development}

It has already been suggested that interaction via digital communication platforms has become an everyday, increasingly dominant form of adolescent interaction. In particular, so-called texting, the 'digital writing' (Dürscheid \& Frick, 2016, pp. 14) surpasses both the telephoning and the face-face interaction in the quantity of use among adolescents in the US since 2009 (Lenhart et al., 2010). 
And, as a student has reported in one of my seminars, it is also sometimes preferred to communicating problems among friends in a meeting. Or a 15-year-old in Katie Davis Interview Survey: 'If I'm having a really big problem, I'm probably в в (Blackberry Messenger) to my friend instead of saying it to her face ... Sometimes it's just easier to type it '(Davis, 2012, pp. 1531). In this study of $2012,47 \%$ found it 'easier to share personal feelings online than offline' (Davis, 2012, pp. 1533).

For Germany, the 2015 JIM study shows that telephoning 'is in fourth place of mobile phone activity', 'it plays a subordinate role today in the daily lives of young people' (pp. 47). 'The most popular variant of use, on the other hand, was the sending of text messages. In 2018, WhatsApp ranks second to YouTube's favorite Internet sites (JIM, 2018, pp. 34) and 87 percent of the 12 to 19-year-olds 'the most important offer' (JIM, 2018, pp. 36).

Before we take a micrological look at empirical texting interactions in different variants and contexts, we can ask ourselves, in the sense of a first sensitization, why this 'writing is so popular'(Dürscheid \& Frick, 2016, pp. 16), with some of the following characteristics later on will take up as explanatory approaches again.

Texting, as a 'silent form of communication' (Dürscheid 2016 \& Frick 2016, pp. 17), unlike telephoning in public spaces (such as buses and trains), allows private communication both locally and temporally unrestricted. The communication is 'time-delayed (asynchronous)' (Dürscheid \& Frick, 2016, pp. 17) and can be answered at any time.

Compared to traditional sMS communication, newer communication platforms on the smartphone, such as WhatsApp, provide a personal assignment of the messages, so that despite the asynchronicity a 'dialogue feeling' (Dürscheid \& Frick, 2016, pp. 39) is generated. The fact that you can usually see whether someone is online and writes, in contrast to the email communication increases the impression of immediacy and spontaneity, but also pressure to respond in a timely manner.

Initially, for reasons of cost and time, an unwanted or deliberately spontaneous and deliberately negligent, 'conceptually oral' (Dürscheid \& Frick, 2016, pp. 61) so-called 'SMS style' or 'SMS writing' (Dürscheid \& Frick, 2016, pp. 41) has developed over time, but has been changing ever since Framework conditions, such as when 'many SMS are clearly less than 160 characters long, but nevertheless have such writings' (Dürscheid \& Frick, 2016, pp. 41).

In terms of all telex formats, digital writing appears to be associated with a degree of devaluation of delayed, written communication, due to the reduction of social impositions and effort that require greater engagement and generate liability. 
In the century of the letter, for instance, in the eighteenth century, 'a regular correspondence was used as a sign of friendship and connectedness; the great poets (Lessing, Goethe, Schiller, and others) wrote letters' (Dürscheid \& Frick, 2016, pp. 57).

Telegrams, postcards and letters, as Dürscheid and Frick point out (Dürscheid \& Frick, 2016, pp. 55), continue to enjoy a high reputation so that they can express a special appreciation with them. The counterpart's presence is also in the postcard, which has his / her writing, signs of use and transport. Appeal and the gift of transient lifetime are the prerequisite of commitment and appreciation and will continue to be perceived.

On the one hand, the digital writing bypasses socio-spatial demarcations, removes communicative resistance and impositions, and on the other hand calls for high-frequency or permanent participation.

\section{A Critical Reconstructive Socialization Heuristic ${ }^{1}$}

\section{1}

\section{The Structure of Socializing Forms of Interaction}

Due to its undeveloped autonomy the child and the juvenile are necessarily embedded in socializing, or to use Kegan's (1982) words, 'embedding cultures.' In comparison with the role-shaped, specific social relations of adult life, which are structured by the logic of contract, primary embedding cultures can be characterized as diffuse or unspecific forms of social relations. What is substantial for them is that one cannot define and clearly limit them in the form of a catalogue of expectations and responsibilities. As such they are relations between whole persons and not between interchangeable role bearers. Accordingly to Parsons (Parsons \& Shils, 1951, pp. 87; Parsons, 1951), the one who excludes an issue carries the 'burden of proof.'

Following Oevermann (1996, pp. 113), who sees the nonsubstitutability of the personnel as a central characteristic of diffuse social relations, the following structural characteristics of diffuse or unspecific social relations can be differentiated:
the expectation of permanency,
unconditional trust,
the affective bonds, and
the participation of the body.

1 The following heuristic and methodological considerations are also presented in Zizek 2017a, $2017 \mathrm{~b}$ and 2020). 
Diffuse social relations are not entered into as limited in time. While in roleshaped or contract relations unconditional trust would be unsuitable for life, with diffuse social relations the opposite is the case. The same goes for a lack of affective connection and physically transmitted affection. The prototype of diffuse social relations is constituted by the relations within the family. Parsons (1973) has highlighted the structural relation- ship between friendship and family.

\subsection{Reconstructive Socialization Theory-Development as a Reconstruction of Social Relations Practices}

The reconstructive theory of socialization (Zizek 2018) assumes that the adolescents acquire their social competences primarily in the participation in interaction practices, by experiencing the social structure of them and reconstructing them practically. So you learn in practice, not through explicit learning or instruction, how to act in these interaction contexts in order to participate. They reconstruct the logic of these socialization practices.

Looking now at the classical, traditional socialization practices, motherchild relationship, family, school, peer group, we have in this sequence of dyads, triad, school class and peer interaction an increase in social complexity and imposition on the adolescents. They challenge them to an understatement, an increasing stripping off of self-centered attitude.

For example, the infantile dyad is a particular interaction practice with only one counterpart, which structures the interaction and, as a rule, does not leave the relationship even in the case of irritation. Nevertheless, the child has to communicate about hunger, for example, to help with simple actions such as breastfeeding or wrapping. The familial triad is an interaction practice with two or more counterparts, so that structural jealousy arises, for example, one has to learn to stand waiting. The school class is a structurally universalistic interaction practice, not particular, not oriented to achievement ascription (Parsons 1951). Peer relationships generate an interaction practice, which are structured together relatively autonomously (Piaget 1983) and whose existence relies on mutual commitment.

\subsection{Autonomy as a Human-Specific Ability, Need, and Aim of Socialization}

Significant basic theoretical positions share a common approach in that they put the crisis structure of human life at the center of their anthropological models. The criterion for life in Helmuth Plessner's (2019) philosophical anthropology is positionality. The incessant mediating work between impulses of 
the environment and the body generates the centric form of positionality, which is animal-specific.

The social human adopts the voices of the socializing primary group. The conflicts that now occur between body and group relatedness and between contradictory voices of the group are movements away from the center, generating the capacity for reflexivity, the human-specific eccentric form of positionality. A new type of situation emerges, the crisis, a situation that demands a decision (König, 1994).

We can understand the subject as the agency which responds to crisis. With centric and eccentric positionality we can differentiate between the two sides of the subject, corporeality and reflexivity. In the everyday life of the adult human, crises are indeed exceptional situations, insofar as routines usually tell us how to decide. However, 'it is precisely these exceptional situations in which the subject constitutes her/ himself as autonomous' (Garz \& Raven, 2015, pp. 29). Autonomy as the human-specific ability to perceive and to cope with open life situations must therefore be considered a key objective of successful socialization.

\subsection{Toward a Critical Socialization Perspective}

The structural characteristics identified with Parsons and Oevermann and which characterize primary socialization practices as relationships between whole persons are the prerequisite for the primary embedding cultures that fulfill the following three functions: holding, letting go, and staying put for reintegration (Kegan, 1982). If these successive functions succeed, they support a process of development and separation (Oevermann, 2004), in which the person being socialized draws her/his boundary anew again and again (Kegan, 1982), and by which, as already described above, her/his potential for autonomy grows (Garz \& Raven, 2015).

I would like to make two further notes on the characteristics of the developmental process, which is embedded by socializing relations. Both Oevermann and Kegan regard the socialization and development process as one that is crisis ridden and can fail. Thereby crisis means, 'following Robert Kegan, always both the possibility to win and to lose. And only if we get used to our 'life project', ready to dare the new and leave the old, can we develop' (Garz, 2008, pp. 10). Thus, development, formation, experience, and an increase in potential of autonomy presuppose a readiness for irritation and crisis.

It is important for the present study that developmentally relevant, socializing interactions (natural and artificial therapy) are characterized centrally by the structural characteristics of diffuse social relations. These ensure a holistic 
attention and care, which holds and lets go, and which contradicts and stays put for reintegration.

\subsection{Essential Characteristics of Adolescence}

Supposedly the simplest concept of adolescence is the transition from childhood to adulthood. In this context adolescence is a universal phenomenon even though through initiation in premodern times, it could be shortened to a few months (Piaget, 1983, 1986; Erdheim, 1982, King, 2019). Adolescence represents itself as a development phase of increased, potentially innovative and at the same time fragile means of dealing with social reality and with oneself. Thus, adolescents are on the one hand the social group that most quickly integrates new technologies such as 'wireless communication technology' (Castells, Fernández-Ardèvol, Qiu, \& Sey, 2009, pp. 252) into their own life practice, but on the other hand are particularly vulnerable to risks such as cyberbullying.

\section{An Explanation of the Specificity of the Methodical Approach}

\subsection{The Constitutional Theory of Objective Hermeneutics}

The specificity of the human-specific positionality has already been addressed by the philosophical anthropology of Plessner. Plessner's observation that the centric positionality is preserved in man is significant as the human-specific form of positionality is thus characterized by the coexistence of centric and eccentric positionality. Characteristic of centric positionality is the implicit decision mode. One could also speak with Kahnemann of quick thinking.

It is significant that centric positionality precedes eccentric positionality and maintains a central role in the handling of everyday life situations. Adolescents, as well as adults, perform acts that she is not aware of while carrying them out. The precedence of the intuitively operating centric positionality means that we always act and have always been characterized before we extend ourselves in an eccentric position and develop self-images.

\subsection{The Basic Methodological Assumptions and Procedures}

According to these constitutional assumptions, human life and the traces or protocols which it leaves behind have an expression character (Zizek, 2012; Wernet, 2014). In these protocols, the entire process of decision-making with its conscious and unconscious intentions and dispositions comes to light.

The central objective-hermeneutic procedure of interpreting the meaning of an action is the comparison with options excluded by this action. The 
meaning of the selected action option is determined by the options that are not selected. The objective meaning of the omission of the greeting response is the 'rejection of a common practice.'

If one examines such selections, which are always necessary at every sequence, over a certain distance, then sooner or later a specificity of the choice becomes apparent. This is called a Fallstruktur (case structure). The reconstruction of the structure of a case is the core aim of an objective-hermeneutic analysis. The concept of structure emphasizes that the specificity of the choice is not arbitrary and randomly varied, but comes from a case-specific structure of dispositions.

As clarified above by the distinction between centric and eccentric positionality, objective hermeneutics reconstructs, above all, meaning structures that are latent, i.e., beyond the self-understanding and self-image of a social practice.

\subsection{The Revealing Force of the Sequence Analysis Procedures in the Present Investigation}

Objective hermeneutics thus offers methodological procedures that are capable of analyzing social action independently of the self-perception of the actors. One can therefore analyze what the subject does or what it means to act in a certain way.

In this context, it is a further advantage of the method that by means of the above-described methodical procedure, everyday natural things in the world such as a greeting or the opening of a personal account are viewed at a distance through this minute examination, allowing their complex structure to be brought into view.

Exemplary Reconstruction of Digital Interactions and Interaction Formats

\subsection{Non-anonymous Adolescent Internet-social Interaction in the Chatroom WhatsApp}

In the following is a highly condensed sequence analysis of a chat interaction. Tom, 25, was asked to copy us in on a chat with his best online friend, whom he also meets offline. The following sequences have been translated by me into English. The following presentation serves to illustrate not only the central theses but also the method:

20:28h - Tom: Peter Panda

Usually one can call someone by name in the street if she/he has not yet seen the other. This way you can get the person's attention. The greeting is then 
usually made up: 'Peter, hi, how are you?' These situation conditions are not present here. Tom cannot see Peter, nor will a greeting be made up. Here the central methodical procedure of varying contexts is used, in which the present statement would make sense. In this way, its implicit meaning is determined in more detail.

Another situation in which such an invocation could take place would be to ask late at night for a shared overnight stay: 'Peter Panda ... are you (still) awake?' One does not see the person in the dark and does not know if she is already/still sleeping. The commonality with the chat situation is that Tom cannot see Peter. The difference is that Tom and Peter are both not in the same room.

In the situation of the shared overnight stay, however, a closeness, a common practice is already established. Here the difference between the different contexts is highlighted to show what this utterance means for the actual context. In this chat, Tom addresses Peter immediately in the mode of high closeness and intimacy. Without greeting, he wants to open a regressive interaction. So he tries to skip the usual procedures of opening a social practice, which ensure consideration for the interaction partner's personal boundaries. It becomes very clear here, as was emphasized in the methodological reflection, that Tom, as an everyday subject, was not fully aware of the implications of the meaning of his speech act.

The medium cultivates a remarkable erosion of habits of social interaction with each other. Without any ado, you can be as confidential as possible. The resulting potential for generating regression islands anywhere and at any time seems to arise from the following conditions that this form of communication offers:

1. Shame-reducing absence of the interaction partner

2. Potentially immediate response (while still in the mood!)

3. No public visibility (unlike when talking on the phone!)

23:34 - Peter: Huhu Tom bärchen $<3$ (Huhu Tom cute little bear $<3$ )

After more than three hours Peter answers with 'Huhu Tom cute little bear (heart)'. Tom's intimate mode of address above, however, clearly suggests, as shown here, that the response will be faster. You notice here how the expectation arises that one should constantly be online. Tom's expectation has been disappointed here by reality.

'Huhu', for example, is called out when playing hide-and-seek, when you do not know where and if someone is there. Peter says, so to speak: 'Are you still there, my sweet Tom ...?' Peter is trying to heal this damage to Tom's request for a spontaneous, intimate communication. Peter signals here: I'm ready to talk now, I'm here. 
It is noteworthy here that in order to be able to send such spontaneous, regressive messages, sooner or later one has to get used to the fact that it may not be possible to obtain the desired answer. So a binding liability-free space must be built: It is always assumed that it may not work.

23:39 - Tom: Na? Alles gut? (Everything all right?)

Tom asks about Peter's condition. The question, however, has a reproachful character insofar as Tom expresses in it a solicitude that can only have been caused by the fact that Peter answers so late: 'Where are you from now, are you all right?'. Some upset is expressed, but also quickly exhausted. Online interaction creates a problem of time management. The potential reachability makes any non-availability need explaining? This contrasts, for example, with e-mail communication, in which even urgent matters can still be dealt with one day later.

With his question, Tom plays the ball back to Peter. He shows a relatively neutral interest, says nothing of himself. Tom has already withdrawn from his initial intimate mode of addressing here. Peter has to say something now.

Tom's first message has, in retrospect, only got the status of a test balloon, with which the other can do what he wants. It's different to call an important person who was important. More than an initiation, this is just a game with an initiation.

If this handling of relationship is typical of Tom and Peter, then this form of non-binding handling of relationship lacks all possibility of experience. Such as, for example, the experience of offense and rejection. But this experience is constitutive for ego and life stabilization. The strategy of the present communication is to avoid the possibility of offense and rejection by avoiding a serious relationship.

23:51 - Tom: I am Sunday around noon in KA and have some time. What do you

think of a coffee or something like that?

Tom had to wait for eleven minutes for Peter's answer and this seems unbearable. Peter lets Tom down, his last message ('huhu ...') gave the legitimate expectation that he is now ready for a conversation. Since Peter had already reported as being ready to talk, it must be assumed that either Tom's latent charge for Peter already included too much liability expectancy. Or Peter does not feel obligated by his answer and in the meantime may again have done something else. Both readings confirm the noncommittal / liability game highlighted above.

Tom now seems to change to another level of communication due to this new rebuff. In contrast to the first three sequences one could write the present one to each one. The intimate exchange is thus initially finished, here is a 
retreat instead. Instead of emphasizing that he would like to meet Peter and then to mention that there was a possibility on the weekend, Tom points out that he is anyway close and also just wants to fill a short period of time. At the latent level, he now retreats from Peter and defines his interest in Peter as more peripheral.

Peter's refusals do not prevent Tom from encouraging a meeting anyway. Instead of withdrawing in the wake of disappointment at the failure of his desired interaction, he pragmatically looks at what else can be extracted from this relationship.

The further interaction of Peter and Tom for the next few months can be summarized as follows: Peter is quite surprised when Tom writes to him shortly before the scheduled date. Peter was still sleeping because he had been out late at night. The exonerating non-bindingness is therefore also here again.

After the one-hour meeting there is no contact for 11 days. And similarly it echoes the pattern for all further interactions: Short non-binding phases of initiation alternate with sometimes very long breaks.

\subsection{What Kind of Help and Support do Adolescents Find in Anonymous Website-mediated Interaction with Peers}

The following section analyzes anonymous adolescent interactions that took place via the A Thin Line (ATL) social media site launched by MTV in 2010. MTV provided this online space for adolescents to report on experiences in their youthful living environment and share social issues through a brief initial post in anticipation of receiving ratings and brief comments. There is a character limit for personal descriptions as well as for comments. Do juveniles with social problems find experiences in the online space, which are helpful for them and available only there?

As an argument for the peer-to-peer structure, it is generally stated that there is a 'high preference for help from informal sources', especially for interpersonal and emotional issues.

As an argument for the online context is usually cited, such artificially designed for help online interaction rooms would reduce inhibitions (Suler, 2004), online forums may diminish barriers, such as self-consciousness or shame, that often prevent help-seeking offline (Barker \& Adelman, 1994).

With their reference to the provision of remote rural areas, to parents who are hard at work, to physical limitations and to the reduction in the time spent by the therapists, Boettcher and Berger in their discussion of internet-based psychotherapy actually defensively emphasize only secondary motives that are not related to the therapeutic practice itself (Boettcher $5^{8}$ ). 

Comments

Linda: 'At my old school ...'

In the first sequence of the presented anonymous personal account, a fifteen-year-old girl, henceforth called Linda, refers to her old school.

The absence of conversation openings is, as we saw above, not uncommon in social media contexts. Openings by greeting formulas or introducing oneself represent a consideration for the personal boundary, the privacy of the other.

'... \& neighborhood ...'

This sequence makes it clear that a change of location has also taken place. The incident yet to be named thus refers to the entire lifeworld of Linda.

'... i was teased horribly ...'

The range of meaning of 'teased' reaches from 'banter' to 'annoying and harassing someone', whereby the adverb signifies a negative reading.

Linda suggests here that she has been harassed in her entire life context. Linda gives the dramatic impression that her entire environment has been busy bullying her, and nobody seems to have shown solidarity with her, which seems overwhelming.

The assignment regarding the initiators is clear: all the others. Linda, on the other hand, seems to have no part in it. The information in the presented case can therefore only provoke indignation among the readers.

'... about how I acted ...'

Linda names what has led the others to their spitefulness and she doesn't present a concrete situation that would allow the reader to form their own image. The others disturbed Linda's entire demeanor.

'... how proper i talked ...'

Linda differentiates now 'how i acted', to which a noble usage belonged. The question was whether, by reason of her background or an individual decision, she had utilized this usage, which might has seemed as an attempt of distinction, in order to possibly differentiate herself from her environment.

This differentiation does not reveal any concrete situation, as did how i acted'. Rather, an individual free space is addressed, which actually belongs to each individual.

'everything'

The just opened differentiation has been interrupted and leveled again. 
Linda differentiates neither regarding to the naming of the causers nor regarding to the elements of the situation: everything about her presence upset the others.

Even in retrospect, Linda is in a state of complete lack of understanding and the situation is considered as not mastered for her, which overstrains her, but also blocks the possibility of clarification. In a personal conversation someone would ask for a description and examples.

Due to the missing possibility of query and the shortness of contributions required by the character limit of this online interaction format Linda may remain in this mode of non-clarification. In the absence of information provided by Linda, she receives only supportive and approving response.

'i wanted to die'

By naming the subjective effect of the attacks by the others, the narration is further dramatized. Linda was extremely desperate and saw no way out but to take her own life.

'... i transfered ...'

Linda mentions the already discussed change of school and location as an active, determined response to the unsustainable, dramatic situation.

She left her parents out of the situation, which makes Linda accentuated as a strikingly determined, autonomous and flexible subject.

Linda hides potential personal responsibility in relation to her problematic situation as well as possible positive, supporting shares on the part of their parents. She profiles herself as beneficial.

'should I have done something'

Linda now addresses the reader directly with a question. Since she has done something ('i transferred'), the question must relate to the time and situation before the change of location. It can only be a question of whether she should have actively taken action against the attacks instead of avoiding them. She could have asked teachers, parents or other people for assistance. This could be a surprising, self-critical twist, in which she would seriously question her former actions, which would contradict the previous hypotheses. Linda portrays the former environment as thoroughly hurtful and malevolent, but considers herself autonomous and demanding, so that the reader has no clues to seriously address this issue. This behavior is merely a call for approval.

'I have to go back this summer to stay at my dads' 
The reason of the question is not a new requirement for a critical retrospective on her own actions, but Linda has to return to her father's old place of residence for the coming summer.

The fact that her parents are obviously separated puts her portrayal of the change of location in a different light. This was contrary to her representation apparently not initiated by her, but by the separation of the parents.

'what should i do?'

If the question 'should I have done something?' has opened up a possible selfreflection, the presented question is only asking for practical advice.

5.2 .2

$$
\text { C1 - First Comment }
$$

'Who cares what those other people have to say.'

$\mathrm{C} 1$ makes a one-sided assignment of the problem and thus corresponds to Linda's intention. With 'those other people', a blanket devaluation of Linda's former interaction partners is made, so that here $\mathrm{C} 1$ praises indifference as a general attitude that $\mathrm{C} 1$ has already realized for her/himself and with which Linda's problems would be solved immediately, but she does not yet have this condition reached. Here, $\mathrm{C} 1$ propagates her/himself as an invulnerable, successfully indifferent subject, but this radical, blanket solution doesn't refer to Linda's problems.

'Yu should want to be hated by what yu are, instead of loved by what yur not!'

There is a fundamental individualism of $\mathrm{C} 1$, according to which a consideration and adaptation to the environment means a deformation of the individual disposition.

In addition to the artful design $\mathrm{C} 1$ also mentions a specific ability of proof as a part of this smart lifestyle. In C1's schema of self-realization, it is considered as a special proof to provoke aversion and outrage in the environment.

$\mathrm{C} 1$ uses this online context as a stage to put herself/himself in scene with her/his idea of personal probation. Here, the interaction format is misused for self-staging.

\subsection{3 $\quad \mathrm{C}_{2}-$ Second Comment}

'I think you made a good choice for yourself by moving away.'

$\mathrm{C} 2$ encourages Linda, on the one hand, moving away was a good decision, but on the other hand $\mathrm{C}_{2}$ attenuates this assessment in a threefold way with the 
expressions 'I think', 'good' and 'for yourself'. In contrast: Moving away was the right choice.

By this threefold mitigation, $\mathrm{C} 2$ takes pressure out of the situation in contrast to $\mathrm{C} 1$ and doesn't incite Linda any further. In C2's opinion everyone should act individually to her/his possibilities.

In contrast to $\mathrm{C} 1, \mathrm{C}_{2}$ takes a closer look at Linda's description and question, while $\mathrm{C} 1$ uses his comment for self-staging. $\mathrm{C} 2$ 's behavior acts as a de-escalating effect.

'When you go back for the summer, avoid all the jerks.'

$\mathrm{C} 2$ agrees with Linda's one-sided description of the problem and he attributes the causing clearly to the others. $\mathrm{C} 2$ treats Linda's problem accordingly just for the period of this summer.

Linda's former interaction partners are devaluated by $\mathrm{C}_{2}$ as well as previously by $\mathrm{C} 1$ but $\mathrm{C} 2$ does not recommend this behavior as a common attitude in contrast to $\mathrm{Cr}$.

C2's comment is like a pat on the back, a hug for a fellow human being in a digital way.

What do Social Media Cultivate in the Examples Analyzed?

\subsection{The Non-anonymous Example of Interaction}

In the non-anonymous interaction a remarkable erosion of habits of social interaction was identified that ensure respect for the personal boundaries of the other person. What is made possible by this erosion of polite manners? There has been a potential for generating regression islands anywhere and at any time.

The normal expectation of being constantly online robs the individual of spaces for autonomous experience and conveys an inevitable, deceptive sense of security.

The necessary failure of the digital promise enforces a noncommittal tolerance and cultivates a stoic pragmatism: One only checks out what one can get out of the individual relationship.

The social media interaction that I analyzed as an example lacks key qualities of a socialization interaction. In the case of traditional instances of socialization, such an unattached and filtered interaction is already an expression of its failure. In these traditional instances of socialization, you know each other; you get involved. One must take account of the situation of the other. You do not just get the desired reactions. 


\subsubsection{The Anonymous Interaction Example}

As part of an examination of socializing quality, it becomes clear that unlike friends, parents and peers or educators and therapists, the reader of Linda's problem description has no knowledge of Linda's character or biography.

This case-specific knowledge is selectively examined, collected and methodically controlled by representatives of the artificial therapy in the interaction process.

Parents, peers or friends as participants of natural therapy know each other, know weaknesses and strengths of the subject, her/his biography and background. In a conversation about a social conflict this information is intuitively always available. On the basis of this knowledge they are enabled to make relativizing or critical remarks.

The interaction format allows Linda, on the one hand, to portray the conflict in a much reduced manner and to hide possible intrinsic proportions and, on the other hand, to reflect the proportion of others subjectively. Socializationrelevant offline practices are better options for concretization by the possibility of inquiries and requests.

It is noticeable that the three commentators can't perform this task, in some cases they even misuse it for their own purposes such as self-staging.

The socialized subject usually receives a permanent support and orientation by socialization-relevant practices. By contrast, in online contexts there is on the one hand the danger that only temporary and selective interest are prevailed by the users and on the other hand that users disappear when things get uncomfortable, exhausting or boring.

Nonetheless, there can be received a little bit of human warmth, temporary understanding and encouragement in online contexts, but nothing more.

\section{1 .2 \\ Interaction Characteristics and Socialization Effects Cultivated by} the Structure of the Website

In the following, against the background of contrasting existing interaction with traditional practices of natural and artificial therapy, we will focus on the characteristics of interaction that are cultivated by the structure of websites such as the present one.

It can be emphasized that eliminating the need to open up interaction and anonymity removes hurdles and impositions of interaction. This is commonly cited as an advantage. However, a closer, structural analysis gives cause for skepticism.

Anonymity, for example, eradicates the need for self-exposure, which in therapeutic contexts, however, represents an essential, de-dramatizing, problem-recognizing component of the self-healing potential. The elimination of the need to open the interaction allows an egocentric structure of 
participation. You participate, how long you want, when you want. Structurally, this interaction structure promises an always available community without claims.

This interaction structure cultivates a neglect of significant social interaction skills and practices. A friendship, for example, erodes without a corresponding commitment and consideration. Of course this is in stark contrast to the explicit intention of this and other websites.

By reducing the possibilities of expression and reciprocity, the interaction structure, which by no means restricts itself to this website, opens up new possibilities of dethematizing, filtered interaction.

The delay of the phase and the writtenness of the interaction erases and relieves of the structure of face-to-face interactions characterized by spontaneity and self-exposure and opens up a new form of controlling one's own utterances. The twitter analog character limit relieves of social impositions such as terminating an interaction and commitment, it always apologizes proactively for the brief admission.

The non-existent opportunity for requests from the commentator also excludes that one might have to represent the social conflict more differentiated.

Interaction Characteristics and Cultural-historical Tendencies

The analyzes show an erosion of established social boundaries and procedures for the generation of binding interaction. The digital writing makes it possible to start from any place at any time an intimate interaction without opening. Temporal and spatial conditions have so far represented social barriers that could only be overcome at certain times and with specific procedures.

In the present case, this reduction in social resistance makes possible the potential of regressive islands that are available everywhere and erodes the binding nature of the interaction by limiting personal involvement. Complementarily, the necessary failure of the digital promise of constant availability enforces a noncommittal tolerance and cultivates a stoic pragmatism: One only checks out what one can get out of the individual relationship.

In some football clubs, for example, coaches are increasingly demanding that they only cancel their participation in training by telephone. Since then, absenteeism has dropped significantly.

The erosion of spatial and temporal social boundaries undermines previous dosing functions. They are handed over to the adolescent, as can be illustrated by the example of porn consumption.

In addition, the requirement of certain social relationship experiences are undermined, a habitualized avoidance of bondage may protect against 
disappointment, but also against the experience and mastery of certain developmentally relevant forms of relationships.

Overall, digital media cultivate the reduction of presence and the training of philobatic attitudes in which, as Michael Balint has described (1987), settles with the spaces between the interactions.

These cultivations are to be understood against the background of cultural tendencies that separate the individual from the contexts of origin. In this tendency, the steering of the individual since the 19th century has changed from steering through internalized attitudes to other direction, as Riesman has described this change in modernity. The digital media make it possible to perceive oneself permanently as in a thin protective cloud of resonance. $\mathrm{O}_{2}$ advertising, for example, has chosen the image of an intra-uterine existence in order to illustrate this feeling; one is constantly under water, so to speak in undivided resonance water.

The fast pace of ads on websites or the practice of erotic selfies activate the individual, one should not take too much time, and permanently evaluate one's own market value.

The dissolution and endowment of the individual with media that postpone being together and, for example, promise comforting moments of happiness by sending photos, open up enormous rationalization potential for a business-oriented lifestyle in which all time slots should be used accordingly.

The benefits of this development are aimed primarily at the social sphere of professional relationships of the adult world, which could also be termed society. Here are also the weak ties to locate, which has addressed Granovetter (1973).

Community relationships in which growing up usually takes place and which provide the above-mentioned, natural therapy are damaged by the mentioned interaction characteristics, the digital media erode 'communal relationships' (Rosa 2010: 177). This erosion has a long history, as Putnam called it by the term 'social capital'. The digital media, however, seem to continue to cultivate this erosion in the manner mentioned and very effectively.

Our analysis shows that with their social offerings, the digital media does not substitute for these sustaining cultures, even though they appear to excite it.

\section{References}

Barker, L. A./ Adelman, H. S. (1994). Mental health and help-seeking among ethnic minority adolescents. Journal of Adolescence, 17, 251-263.

Balint, M. (1987): Thrills and Regressions, London: Taylor \& Francis. 
Boettcher, J./ Berger, T. (2018). Internetbasierte Therapie am Beispiel sozialer Ängste. In: O. D. Kothgassner \& A. Felnhofer (Eds.), Klinische Cyberpsychologie und Cybertherapie, 57-64, Wien: Facultas.

Castells, M., Fernández-Ardèvol, M., Qiu, J. L., \& Sey, A. (2009). Mobile communication and society. A global perspective. Cambridge, MA: MIT Press.

Common Sense Media (2015). The common sense census: Media use by tweens and teens. http://www.commonsensemedia.org/census.

Davis, K. (2012). Friendship 2.0: Adolescents' experience of belonging and selfdisclosure online, Journal of Adolescence, Vol. 35, Issue 6, 1527-1536, https://doi .org/10.1016/j.adolescence.2012.02.013.

Dürscheid, C., \& Frick, K. (2016). Schreiben digital. Wie das Internet unsere Alltagskommunikation verändert. Stuttgart: Alfred Kröner Verlag.

Erdheim, M. (1982). Die gesellschaftliche Produktion von Unbewusstheit. Frankfurt am Main: Suhrkamp.

Garz, D. (2008). Vorwort zur deutschen Ausgabe. In R. Kegan (Ed.), Die Entwicklungsstufen des Selbst. Fortschritte und Krisen im menschlichen Leben (pp.9-11). München: Kindt.

Garz, D., \& Raven, U. (2015). Theorie der Lebenspraxis. Einführung in das Werk Ulrich Oevermanns. Wiesbaden: Springer VS.

Granovetter, M. (1973). The strength of weak ties. American Journal of Sociology, 78, 1360-1380. doi:10.1086/225469

Kegan, R. (1982). The evolving self. Problem and process in human development. Cambridge, MA: Harvard University Press.

König, J. (1994). Kleine Schriften. Freiburg: Alber.

Lenhart, A./ Purcell, K./ Smith, A./ Zickuhr, K. (2010). Social Media \& Mobile Internet Use Among Teens ans Young Adults, Pew Internet \& American Life Project, Washington, https://files.eric.ed.gov/fulltext/ED525056.pdf.

Lévi-Strauss, C. (1960). Strukturale Anthropologie II. Frankfurt am Main: Suhrkamp.

Medienpädagogischer Forschungsverbund Südwest (2015): JIM-Studie 2015. Jugend, Information, (Multi-) Media. https://www.mpfs.de/fileadmin/files/Studien/JIM/ 2015/JIM_Studie_2015.pdf.

Medienpädagogischer Forschungsverbund Südwest (2018): JIM-Studie 2018. Jugend, Information, Medien. https://www.mpfs.de/fileadmin/files/Studien/JIM/2018/ Studie/JIM_2018_Gesamt.pdf

Oevermann, U. (1996). Theoretische Skizze einer revidierten Theorie professionalisierten Handelns. In A. Combe \& W. Helsper (Eds.), Pädagogische Professionalität. Untersuchungen zum Typus pädagogischen Handelns (pp. 70-183),. Frankfurt am Main: Suhrkamp.

Oevermann, U. (2004). Sozialisation als Prozess der Krisenbewältigung. In D. Geulen \& H. Veith (Eds.), Sozialisationstheorie interdisziplinär. Aktuelle Perspektiven (pp. 155-183). Stuttgart: Lucius \& Lucius. 
Parsons, T. (1951). The social system. Glencoe, IL: Free Press.

Parsons, T. (1973). Soziologische Theorie. Darmstadt: Luchterhand.

Parsons, T., \& Shils, E. A. (1951). Values, motives and systems of action. In T. Parsons \& E. A. Shils (Eds.), Toward a general theory of action (pp. 47-275). Cambridge MA: Harvard University Press. doi:10.4159/harvard.9780674863507.c4.

Piaget, J. (1983). Das moralische Urteil beim Kinde. Stuttgart: Klett-Cotta.

Piaget, J. (1986). Die moralische Entwicklung von Jugendlichen in primitiven und modernen Gesellschaften. In H. Bertram (Ed.), Gesellschaftlicher Zwang und moralische Autonomie (pp. 118-125). Frankfurt am Main: Suhrkamp.

Plessner, H. (1999). The limits of community: A critique of social radicalism. Amherst, MA: Humanity Books.

Plessner, H (2019). Levels of Organic Life and the Human: An Introduction to Philosophical Anthropology (Forms of Living), New York: Fordham University Press.

Rosa H., Gertenbach L., Laux H. \& Strecker D. (2010). Theorien der Gemeinschaft. Hamburg: Junius.

Albert, M./ Hurrelmann, K./ Quenzel, G./ TNS Infratest Sozialforschung (2015). Shell Jugendstudie, Jugend 2015, 17. Shell Jugendstudie, Frankfurt am Main: Fischer Verlag.

Albert, M./ Hurrelmann, K./ Quenzel, G., Public, K. (2019). Shell Jugendstudie, Jugend 2019, 18. Shell Jugendstudie, Basel: Beltz

Suler, J. (2004). The Online Disinhibition Effect, CyberPsychology \& Behavior, Vol. 7, No. 3, 321-326, https://doi.org/10.1089/1094931041291295.

Turkle, S. (2015). Reclaiming conversation. The power of talk in a digital age. New York, NY: Penguin Books.

Wernet, A. (2014). Hermeneutics and objective hermeneutics. In U. Flick (Ed.), The SAGE handbook of qualitative data analysis (pp. 234-246). London: SAGE.

Zizek, B. (2012). Vollzug und Begründung, objektive und subjektive Daten - Eine Parallele? Sozialer Sinn, 1, 39-56.

Zizek, B. (2017). Digital Socialization? An Exploratory Sequential Analysis of Anonymous Adolescent Internet-Social Interaction. Human Development, 6o, 203-232, doi:10.1159/000479082.

Zizek, B. (2018). Tendenzen und Desiderata aktueller Sozialisationsforschung zu Kindheit und Jugend aus der Perspektive einer rekonstruktiven Sozialisationsforschung. In A. Kleeberg-Niepage, \& S. Rademacher (Eds.), Kindheits- und Jugendforschung in der Kritik. 355-388. Wiesbaden: VS.

Zizek, B./Andermann, H. Z. (2020). Analysis of Youth-Oriented Websites. An Introduction to the Qualitative Image-Analytical Methods of Objective Hermeneutics. Beijing International Review of Education, 2, 54-76, doi:10.1163/25902539-00201005. 